\title{
Traditional forest knowledge: Challenges and opportunities
}

Keywords: Conservation; Cultural landscapes; Forest history; Heritage; Indigenous knowledge; Local knowledge; Sustainable forest management

Innovative forest management practices, based on traditional knowledge (TFK) ${ }^{1}$ and developed by rural communities over the centuries, have contributed significantly to the world's natural and cultural heritage by creating and maintaining landscapes of outstanding beauty while helping to sustain production of multiple goods and services that enhance livelihood security and quality of life. Traditional forest knowledge is an integral component of a network of linkages and relations, supported by an overall framework of signs and meanings. It is often based on long historical experience and deep insight into the dynamics of forest ecosystems, and the behavior and characteristics of animal and plant species that are of special economic, social, cultural, and spiritual significance to communities. Strongly rooted in the past, this collective knowledge is critical to the survival and future well-being of local communities, and especially, of indigenous peoples as they try to maintain their distinctive cultural identities and livelihoods, and the integrity and health of the forest ecosystems on which they depend. For many developed societies, the conservation of traditional knowledge and their related landscapes supports the economic development of rural areas, tourism, promotion of local products, the conservation of biodiversity generated by human influence on the landscape, and the quality of life of the population.

That indigenous communities in particular have historically been wise stewards of forests should come as no surprise - most of the world's "primary forests" and biodiversity "hotspots" are located in regions with the highest diversity of indigenous cultures and their associated traditional knowledge and wisdom. Rural areas with a long history of activities that

\footnotetext{
1 "a cumulative body of knowledge, practice and belief, handed down through generations by cultural transmission and evolving by adaptive processes, about the relationship between living beings (including humans) with one another and with their forest environment" (United Nations Forum on Forests 2004; adapted from Berkes et al., 2000).
}

integrate forestry into farming activities have also created a biodiversity that is closely connected to landscape patterns. Cultural landscapes fashioned by traditional practices often shows a high level of habitat diversity due to many different management forms and species introduced over the years to develop specific economic and social functions.

Considering the future scenarios that global warming presents, conservation of TFK should be closely evaluated, as it is often the result of centuries of adaptation to difficult environmental conditions. Its efficacy in coping with challenging environmental conditions depends on the interaction among several factors that must be carefully considered in order to understand their historical success achieved through internal logics that have rarely been formalized into formal science. In traditional rural communities different types of forestland, from scattered trees in the fields to dense forest cover, are viewed as unique ecological systems providing a variety of products and environmental services, including the conservation of water resources. Marginal and apparently non-productive areas, such as steppes and marshes, provide significant quantities of food, water resources, fodder and fertilizer, while specific landscape patterns allow the production of multiple goods with reduced use of external energy inputs. These areas, as well as open spaces used for pasture, are rapidly shrinking, especially in Europe. Greater recognition of their environmental, socioeconomic, and cultural values should lead to greater support for their preservation rather than conversion into high forests, as is often suggested.

The holders and users of traditional knowledge in many parts of the world face significant challenges - continuing encroachment and/or expropriation of their lands, degradation of their forests, and the erosion of their cultures, values, and traditional lifestyles. In many developed societies, technological development, the abandonment of marginal lands, renaturalization, and inappropriate policies are rapidly erasing cultural values and contributing to the globalization of landscape, which are being simplified into areas either managed 
for commercial exploitation or left to natural succession. This trend has been supported by the historical development of forestry, particularly in Europe. Since the early 19th century, the development of modern forestry promoted industrial plantations favoring species suited for timber production, as occurred in Europe with large-scale afforestation of conifers through artificial regeneration and producing even-aged forests. These ideas were spread throughout the world during the 19th century, largely through the colonial administrations of the European imperial powers. This process changed the features of many cultural forest landscapes created by traditional preindustrial societies, both in developed and developing countries. In the 1970s, forestry passed from a phase favoring almost exclusively economic aims, to one paying greater attention to the ecological roles of forests and the value of biodiversity. Unfortunately, the assessment of biodiversity has often neglected components arising from human influence, while monitoring and conservation have focused on "natural" species. The abandonment of traditional landscapes has reduced the diversity of forest management forms, creating simplified landscapes often with reduced biodiversity of habitats linked to land uses and related forest management practices. This neglect of the biodiversity associated with cultural landscapes has also influenced directives and international processes on nature conservation, as well as sustainable forest management strategies.

The protection and preservation of traditional forest knowledge and cultural heritage is an uphill battle for most societies. This is a particular challenge given socioeconomic development pressures, rising exploitation of indigenous forest resources, imbalanced economic and political power relations that usually put local and indigenous communities at a distinct disadvantage, global cultural homogenization, economic globalization, and many other challenges including unfavorable forestry policies (IAITPTF, 2005; Agnoletti, 2006). Traditional forest knowledge and their related landscape are even more vulnerable to threats due to the exclusion of cultural factors in sustainable forest management strategies at the global level. The UNCED conference in Rio de Janeiro in 1992 declared its Agenda 21, formalizing an agreement on a set of forest principles. Although the forest principles do not constitute a legally binding international agreement, they reflect a global consensus that forests should be managed sustainably. Many other meetings, a range of multilateral processes and a plethora of documents at international, regional, and national levels reflected the resolutions of the Rio Conference. Various multilateral processes that concern particular regions or types of forests and now cover $90 \%$ of the world's forests, attempt to clarify sustainable forest management and explain how it could be applied in different regions, presenting in effect a hierarchy of values for the management of forests and woodlands. These processes have also promoted forest certification standards that are applied in several parts of the world.

Certification was introduced as a market-based effort to foster sustainable management of forests, including aspects such as human rights of indigenous populations, poverty alleviation, and respect for conservation legislation. It was initially driven mainly by concerns over the exploitation of tropical forests and reported losses of species from these forests. These protocols, particularly the criteria and indicators included in their structures, do not fully identify landscape histories or culturally important landscapes as central considerations for future management decisions. The fact that cultural values currently play such a limited role indicates the scant consideration given to the role of culture and history in the overall valuation of forests within the paradigm of sustainability developed in recent decades. This paradigm emphasizes the negative role of man in the environment, as an agent degrading the ideal state of "naturalness", which is considered to be the most desirable condition for biodiversity conservation and the overall health of the biosphere. Environmental degradation is without question a real threat affecting the planet. However, several investigations carried out in the fields of forest and woodland history and historical ecology, today generally included into the wider framework of environmental history, reveal a large number of cases where man has created valuable landscapes. Not only from a cultural value standpoint, but also from an ecological point of view, enhancing the overall diversity and improving the conditions of the environment. Failure to coherently address culture and history may very well be a growing weakness that will have to be reconciled if the public is to have confidence in the protocols designed to recognize well-managed forests and, ultimately, sustainable management.

There are, however, some hopeful signs and emerging opportunities. Over the past decade, there has been a marked growth of initiatives by indigenous peoples' organizations, NGOs, intergovernmental organizations and others related to traditional knowledge, and specifically to traditional forest knowledge (cf. ICSU, 2002; UNCCD, 2005). In recent years, the importance of this topic has been emphasized by scientific bodies, non-governmental organizations, national governments, and intergovernmental organizations and policy forums such as the Convention on Biological Diversity, the UN Convention to Combat Desertification, and the United Nations Forum on Forests. One reason for this development is the increasing public support, commitment of local and national governments, and the international forest policy community, to principles of sustainable forest management, based on defined criteria and indicators for ecological, social, economic, cultural, and spiritual sustainability.

At the global level the 1972 UNESCO World Heritage Convention (concerning the protection of the world cultural and natural heritage) promotes the identification, protection, conservation, presentation, and transmission to future generations of the cultural and natural heritage of 'outstanding universal values'. The Convention includes cultural landscapes, considering both material and immaterial elements, but is specifically designed for sites having special importance.

An approach with a different perspective is the one reflected by the European Landscape Convention, an international treaty signed in Florence (Italy) in 2000, now ratified or signed by 33 countries. The convention aims to care for all landscapes, independently of their significance, developing policies for 
planning, conservation and management, as well as pursuing specific landscape quality objectives. However, the convention still needs to be integrated with the European directives concerning rural development, especially the forest action plan that has no specific policies for cultural values. To date in Europe, only the Italian National Plan for Rural Development (2007-2013) has officially included the conservation and development of cultural landscapes as a strategic element. The Italian plan also includes the conservation of TFK, although current forest policies do not directly favor the conservation of traditional landscapes, nor do they allow the restoration of more open landscape patterns, such as wood pastures, once common throughout Europe as well as in many other parts of the world.

The definition of forest management objectives and forest management practices that meet diverse criteria for sustainability requires collaboration among relevant stakeholders. The need for decision-makers and forest managers to consider all relevant knowledge about forest ecosystems and the impacts of forest management options in the development of forest policies and operational practices is being increasingly recognized. While there is a significant and growing body of knowledge and scientific literature in the biophysical sciences and economics that is relevant to the development and application of ecological and economic criteria and indicators of sustainable forest management (SFM), relatively little attention has been paid by the forest science community to the social dimensions of SFM, which include cultural and spiritual considerations, as well as historical management practices.

The role of traditional knowledge in sustainable forest management and conservation of cultural heritage was the focus of a conference held on 11-15 June 2006 at the Italian Academy of forestry science in Florence, Italy - "Cultural heritage and sustainable forest management: the role of traditional knowledge" (Parrotta et al., 2006). This meeting, organized by the IUFRO's Task Force on Traditional Forest Knowledge and Research Group 6.07 "Forest and woodland history", was supported by the University of Florence, the U.S. Forest Service and the Liaison Unit of the Ministerial Conference on the Protection of Forests in Europe (MCPFE), in cooperation with the Italian Ministry of Agriculture, Food, and Forest Policies, the regional government of Tuscany, UNESCO, and the European Society for Environmental History. The conference was a step towards the implementation of the Vienna declaration no. 3 of the MCPFE concerning "Preserving and enhancing the cultural dimension of sustainable forest management in Europe", which aims to develop specific indicators concerning cultural values to improve the existing set of criteria for sustainable forest management enhanced by the MCPFE. The conference attracted 120 participants from 24 countries, including forest scientists, forest managers, and planners, forest policy experts, and representatives from a variety of international organizations and forest policy bodies, including representatives from the UNFF, FAO, UNCCD, UNESCO, the Council of Europe's European Landscape Convention, and the MCPFE liaison unit. An important result of the conference was the establishment of an international expert group to produce guidelines for the implementation of Vienna declaration 3, in order to achieve a full recognition and inclusion of cultural values in SFM by all the 40 member states.

This volume includes a selection of the papers presented during the Florence conference. While the conference included participants from throughout the world, its particular focus was on Europe, where issues related to the conservation of cultural landscapes, traditional knowledge and land-uses, and biodiversity continue to be hotly debated within both the scientific community and forest policy forums. The central trends, issues, and questions explored during the conference included: how traditional forest management practices and their associated traditional forest knowledge have, over centuries, shaped the forests, their biodiversity, and the cultural landscapes of Europe (and elsewhere); how economic conditions, forest and land-use policies and legislation, and demographic shifts have, particularly in recent decades, resulted in sharp declines in traditional forest management and the loss of traditional forest knowledge; and how these historic changes affected the distribution and composition of forested landscapes. Also highlighted were recent efforts to preserve or revive traditional forest management practices to both enhance the economic, social, and cultural values of forests, and to conserve cultural and biological diversity at the landscape level in this era of rapid economic, social, and environmental change. Papers selected for inclusion in this volume examine these topics in a variety of geographic, historical, social, and cultural contexts, and include studies from Italy (Agnoletti; Coppini and Hermanin; Gangemi; La Mantia et al.; Scotti and Cadoni); Spain (Linares; Montiel); the United Kingdom (Holl and Smith; Rotherham); Austria (Johann); Ukraine (Elbakidze and Angelstam); Finland (Siiskonen); India (Ramakrishnan); and the United States (Trosper).

The development of policies, legislation, and land-use (particularly forest) planning systems and management practices that can harmonize environmental, economic, social, and cultural objectives is a major challenge, not only in Europe, but throughout the world. Achieving this balance will require broader participation of local communities, and a better understanding by decision-makers and the scientific community of the knowledge and wisdom of these often-marginalized communities on issues related to forest landscape conservation and management. It is hoped that this special issue of Forest Ecology and Management will encourage further, muchneeded interdisciplinary research on topics related to the past, present, and potential future roles of traditional forest management practices and its associated knowledge, embedded deeply in the socioeconomic and cultural fabric of local and indigenous communities, in fostering more sustainable forest management worldwide.

In closing, we wish to thank the authors of all papers submitted for consideration for publication in this volume. We also acknowledge the invaluable assistance of all those who served as peer reviewers and contributed greatly to the relevance and quality of this special issue: G. Blank, M. Bürgi, F. Cazzola, J. Dargavel, S. Dewhurst, M. Emery, M. Fioravanti, S. Gallini, C. Galvan, E. Goldberg, Y. Haila, T. Harvey, A. Hoover, I. Iriarte-Goñi, K. Kirby, P. Madsen, C. Manuel-Valdés, 
J. Myrdal, T. Neyisçi, A. Ortega, L. Östlund, A. Oteng-Yeboah, M. Paci, G. Piovesan, T. Plieninger, K. Sagheb-Talebi, F. Salbitano, E. Sharma, M. Stenseke, E. Svennson, M. Türker, V. Vos, and C. Watkins.

\section{References}

Agnoletti, M. (Ed.), 2006. The Conservation of Cultural Landscapes. CAB International, Wallingford, UK.

Berkes, F., Colding, J., Folke, C., 2000. Rediscovery of traditional ecological knowledge as adaptive management. Ecol. Appl. 10, 1251-1262.

IAITPTF, 2005. Our Knowledge for Our Survival: Regional Case Studies on Traditional Forest Related Knowledge and the Implementation of Related International Commitments. International Alliance of Indigenous and Tribal Peoples of Tropical Forests, Chiang Mai, Thailand. Available from: http:// www.international-alliance.org/publications.htm.

ICSU, 2002. Traditional Knowledge and Sustainable Development. ICSU Series on Science for Sustainable Development No. 4. International Council for Science, Paris. 24 p. Available from: http://www.icsu.org/.

Parrotta, J.A., Agnoletti, M., Johann, E. (Eds.), 2006. cultural heritage and sustainable forest management: the role of traditional knowledge. Proceedings of an International Conference held in Florence, Italy, June 8-11, 2006. Warsaw, Poland: Ministerial Conference on the Protection of Forests in Europe, Liaison Unit Warsaw, Vol. 2. Available from: http://www.iufro.org/ science/task-forces/traditional-forest-knowledge/.

United Nations convention to combat desertification (UNCCD), 2005. Revitalizing Traditional Knowledge - a Compilation of UNCCD Documents and
Reports from 1997-2003. UNCCD Secretariat, Bonn, Germany, 150 p. Available from: http://www.unccd.int.

United Nations forum on forests (UNFF), 2004. Report of the SecretaryGeneral: Traditional Forest-related Knowledge (E/CN.18/2004/7). Available from: http://www.un.org/esa/forests/documents-unff.html\#4.

John A. Parrotta**

IUFRO Task Force on Traditional Forest Knowledge, U.S. Forest Service, Research and Development, 4th floor - RP-C, 1601 North Kent Street, Arlington VA 22209, USA

Mauro Agnoletti,

IUFRO Research Group 6.07 "Forest and Woodland History", Department of Environmental Forestry Science and

Technology, Faculty of Agriculture, University of Florence, Via San Bonaventura 13, 50145 Firenze, Italy

*Corresponding author. Tel.: +1 703 6054178;

fax: +17036055131

E-mail address: jparrotta@fs.fed.us

(J.A. Parrotta)

${ }^{1} U R L:$ http://www.forestlandscape.unifi.it/. 